\title{
Quantifying the representation of gender in the discourse of the Moroccan tabloid newspapers: a focus on the experiential function of language
}

\author{
Dr.El BiadiMaha \\ (The Department of English, Faculty of Letters and Human Sciences, DharMehraz, Sidi Mohamed Ben \\ AbdellahUniversity, Fez, Morocco)
}

\begin{abstract}
This study investigates the language of Moroccan popular newspapers to discover whether men and women are represented differently. The general hypothesis that the study starts from is that there is a difference in the way the two genders are depicted in these newspapers. By adopting a Critical Linguistic approach, theaim is to explore the linguistic mechanism deployed in order to see where areas of uneven treatment reside. This will mainly be achieved through quantitatively analysing headlines as well as newspaper core texts, to discover whether their discourse displays a meaningful pattern at the level of the experiential function. This research distinguishes itself from most of the Critical Linguistic studies dealing with gender-related differences in language in that it goes beyond qualitatively evaluating newspaper texts, i.e. it does not solely rely on interpreting some particular linguistic structures in order to establish their significance in the discourse.It doesalso quantify the use of these linguistic features used in the news reports, to find out whether they create a socially meaningful pattern, hence providing statistical evidence of the way theyportray men and women in the newspapers under study.
\end{abstract}

Keywords: Critical Linguistics, newspaper discourse, the experiential function, gender representation.

\section{Introduction}

The present paper will be concerned with gender representation at the experiential level of language. I will be particularly exploring the way transitivity system presents men and women in the discourse of the Moroccan popular newspapers, using a Critical Linguistic (henceforth CL) approach, which is one of the most influential strands of CL Linguistics developed in the university of East Anglia by Fowler, Hodge, Kress and Trew (Fowler et.al 1979). As in other CL approaches ${ }^{1}$, its aim is to investigate the way language is used for the reproduction of power relationships.

\begin{abstract}
Language assists in the formation and reproduction ofthe schematic categories in terms of which a society represents itself, by providing labelling expressions which solidify concepts of 'groups', by assigning different semantic roles to the members of different groups, thus discriminating among them and, by imbalance, assisting the practice of allocating power and opportunity unequally among them. (Fowler 1991: 120)
\end{abstract}

CL is considered better suited to test the hypothesis that the present work starts from, which is that men and women are not represented in the same way in the discourse of the Moroccan tabloids. This is mainly because it will enable the linguistic scrutiny of newspaper reports through the use of some linguistic toolsthat will helpin theidentification ofareas of uneven treatment between men and women at the experiential level in the discourse of these newspapers. The objective is to look for textual supporting evidence to show the difference the language of these newspapers displays between men and women.

Taking into consideration that one of the criticisms laid against CL is that it tries to read off significance from linguistic items assuming the subjectivity of the receiver (see Widdowson 1998), the present study adheres to the view that the linguistic structure cannot on its own lead directly to the social meanings and to the general system of values. It is, therefore, deemed necessary to carry out a quantitative analysis to find out whether the linguistic features of interest display a suggestive pattern correlating with the gender of the

\footnotetext{
${ }^{1}$ There are other CL approaches sharing a similar interest in the interaction of language and ideology, the most prominent of which are Fairclough's, van Dijk and Wodak's approaches.
} 
participants in the newspapers.I shall first give a brief definition of what is meant by the experiential function in Functional Grammar (henceforth FG). This will involve discussing the notion of transitivity which will be the main linguistic tool that the study relies on to examine newspaper texts. I will then move onto presenting the statistical findings of the quantitative analysis of thelinguistic features of significance relating to the experiential function of language, as this will give a clearer picture as to how these are deployedin the discourse of the newspapers to depict the two genders. This will help uncover some hidden meanings lying beneath the linguistic structure, which are not explicitly expressed in the news reports in question.

\section{The Experiential Function}

The experiential function is one of the two components of the ideational metafunction ${ }^{2}$ that Halliday talks about in Systemic Functional Grammar, and which Critical Discourse analysts draw upon in their studies, to lay barethe latent meanings that texts carry. This function is concerned with the way experience is construed in language. Because experiences in the world are varied and numerous, language provides a set of processes and participant roles to enable the speaker to fulfil his/her demands to express all types of happenings and experiences belonging to both the internal and external world of consciousness (Halliday 1994: 106). This functional component finds its manifestation at the rank of the clause ${ }^{3}$ in the system of transitivity.

\subsection{Transitivity system}

Transitivity is defined as being "a network of options which constitute the meaning potential for the expression of processes: options in the types of process that we recognise, the various participant functions that may be associated with them." (Halliday 1976: 21). It is the function mainly concerned with actions, relations, participants and circumstances that give content to the talk of interactants. The main purpose behind studying this grammar in discourse is to see 'who is doing what to whom?' in discourse.

In traditional grammar, transitive and intransitive verbs are differentiated by the fact that the transitive verb takes an object while the intransitive does not require one. Halliday's functional grammar theory does not agree with this view, which tends to separate the syntactic structure from the semantic function of language. It suggests, on the other hand, that the linguistic structures that the transitivity system offers are not arbitrary. Grammatical structure fulfils the experiential function and carries specific meanings in discourse and does not have only a syntactic function (Halliday 1978:45).

CL, whose approach is based on Hallidayan FG, exploits the system of transitivity to analyse texts for socially significant patterns. This is because it provides a set of options with different types of meanings, and the choice of a particular structure can bring about a particular meaning, which can be socially significant (Fowler 1991: 71). Transitivity provides the speaker with many ways of describing the same experience. Opting for one structure rather than another can be highly motivated by the social and cultural factors.

Processes that language makes available are best described as being a spectrum. Some of the processes are considered major, namely material, mental and relational, while others, (behavioural, verbal, and existential processes) occur at the peripheries of the main processes, resulting in a hybrid type of processes, which share the characteristics of the pairs of processes between which they occur. I shall at this stage proceed to talking about each type of processes in more detail.

\subsubsection{Material processes}

As their label implies, material processes are the type of processes involving a physical action. "They express the notion that some entity 'does' something - which may be done 'to' some other entity" (Halliday 1994: 110) and involve changes in the world that can be perceived (Martin et al. 1997: 103). The following examples show this:

i- The boy hit the ball

ii- Financial problems pushed him to abandon his studies

\footnotetext{
${ }^{2}$ Besides the experientialfunction, Halliday talks of the Logical component as the second mode of the ideationalfunction, whichisconcernedwith the logical aspect of experience. (Halliday 1994: 179). This logical component of the ideationalmetafunctionis not simplyconcernedwithdescribing the way sentences are constructed, but looks at the particularrelationshipheldbetweenelements in the sentence. The logical aspect of newspapertextswill not bedealtwith in the presentresearch; the analysiswillberestricted to the experientialfunction, and more particularlywithtransitivity structure in the text.
}

\footnotetext{
${ }^{3}$ Note that the experiential function is also realised at group rank and in terms of lexical categorisation (Fowler 1991: 80). The current study will not analyse the experiential function at the level of the group.
} 
In the first instance, 'hit' is about a physical action, whereas the second is about an action 'carried out' by an abstract phenomenon, which is 'financial problems'. This means that the material process obligatorily has an Actor, which can be animate, inanimate or abstract, and an optional Goal. The latter is the participant role towards which the process is directed. In example (i) above, 'the boy' is the Actor of the material process, whereas 'the ball' is the participant to which the material process is directed.

\subsubsection{Mental processes}

Mental processes in FG are the kind of processes related to thinking and feeling. Halliday divides them into three main types: cognition, affection and perception (Halliday 1994:118). They are the kind of processes related to what goes on in the internal world of the mind (Thompson 1996:82). Participants taking part in this type of processes have to be human or some other creatures that the speaker chooses to endow with consciousness, like pets and domestic animals (Halliday 1994: 114). The participant involved in the mental process is labelled the Senser:

iii- They knew that she would accept (cognition)

iv- The cat likes lying down next to the heater (affection)

$\mathrm{v}$ - They saw the sky turn red (perception)

The element that is felt or perceived in the mental process is a fact rather than a concrete 'thing' and is generally referred to as the Phenomenon. They are the type of elements that "cannot do anything, nor can they have anything done to them" (Halliday 1994:115).

\subsubsection{Relational processes}

This type of processes is defined as the process of being. This is to say that a relationship is established between two entities, where "something is being said to 'be' something else" (Halliday 1994:119). They refer to what are traditionally "copula constructions (Martin et al. 1997: 106). In English, relational processes could be divided into three types: 1) intensive 2) circumstantial 3) possessive, which can each be in two modes: the attributive and the identifying (Halliday 1994:119). The former is about class membership, the latter is concerned with symbolising (Martin et al. 1997:106). The following are examples showing the three respective types of relational processes in both modes:

1) Intensive:

viii- The weather is warm (attributive)

ix- My sister is the student (identifying)

$\mathrm{x}$ - The student is my sister (identifying)

2) Circumstantial:

xi- The book is in the library (attributive)

xii- Last month was January (identifying)

xiii- January was last month (identifying)

3) Possessive:

xiv- John has a garden (attributive)

$\mathrm{xv}$ - The garden is John's (identifying)

xvi- John's is the garden (identifying)

In the attributive mode, an entity in the clause is assigned an attribute, and is generally referred to in FG as Carrier, whereas in the identifying mode, an identity is ascribed to an entity. In the identifying mode, entities (identifier/identified) allow reversibility, while in the attributive, they do not (Halliday 1994: 119).

\subsubsection{Behavioural processes}

The behavioural processes share characteristics of material and mental processes. It is typically human and is about physiological and psychological behaviour (Halliday 1994:139). The participant in this type of process is labelled the Behaver and is typically a conscious being "like the Senser; but the process is grammatically more like one of 'doing"' (Halliday 1994:139).

Processes can in some cases be closer to the mental processes as in; "look, watch, stare, listen, think, worry, dream." These processes "construe (human) behaviour, including mental and verbal behaviour, as an active version of verbal and mental processes. That is, saying and sensing are construed as activity." (Martin et al. 1997:109). There is a distinction between a mental process and a behavioural process as the following examples show:

xvii- John was watching the football match 
xviii- John saw them quarrelling

As Martin suggests, the behavioural process 'to watch' in example (xxii) is construed as an activity, and can be unmarkedly in the present continuous. The second example on the other hand, is a mental process and cannot be presented in the present continuous, as it is not construed as activity.

Behavioural processes can be near verbal, where the verbal process is represented as behaviour, like 'chatter', 'grumble'. They can be near material processes as in 'sing', 'dance', 'sit' (up and down). They can also be other physiological processes like 'breath', 'cough', 'faint' (Halliday 1994: 139). Another type of processes that Halliday talks about and which are located between mental and material processes are verbal processes.

\subsubsection{Verbal processes}

These processes are defined in FG as being those of saying. They are not limited only to the verbal way of exchanging meaning and include other forms of symbolic exchanges (Halliday 1994: 140). This means that participants in verbal processes do not have to be conscious beings (Halliday 1994: 140). They are located, in the process continuum, between material processes, as saying involves a physical movement and mental processes because saying reflects a mental activity.

The participant roles taking part in this process are: the Sayer who conveys the saying and the Receiver who receives what is said in the verbal process. Halliday also talks about the Target as a participant role in the verbal process. It is the participant towards whom the saying is directed rather than addressed. The following is an example clarifying this:

xxiv- He cursed him in front of the guests

$\mathrm{xx}-$ John asked the lady for directions

'Him' in xxiv above is the Target as the verbal process is actually aimed at him rather than just addressed, while in example (xx), 'the lady' is the Receiver as she is being addressed questions to which she will give a reply. Verbiage is another component of a verbal process and refers to what is said in the verbal process. Thus, the language used is labelled in the clause to refer to what is said in the verbal process, like 'warning' or 'French', etc (Halliday 1994: 141). Verbal processes are also used to report speech either directly as in 'he said: I'm happy', or indirectly as in 'He said he was happy'. The projected clause of this type of process may be a proposition as in 'he told her the cat ate the fish', or a proposal as in 'They told them that they must work hard'.

\subsubsection{Existential processes}

Existential processes are mainly about existing or happening. This is expressed in structures like the following 'There was a rise in the product price'. 'There', in such processes do not have a transitivity function. The verb used for this type of processes is typically verb 'to be' (Halliday 1994:142). This type of processes involves only one participant, the Existent, being by this different from the relational processes (Martin et al. 1997:109). These are the processes that Halliday identifies in English and the various participants associated with them.

In Arabic, existential processes are expressed through the use of structures such as the following:

xxi-huna:kamahat ${ }^{\varsigma}$ atu qit ${ }^{\varsigma}$ a:rin fi murrakush

- there (is) train station in-Marrakech

- there is a train station in Marrakech

xxii-ka:nahuna:ka?izdiha:run Riqtis`a:di:junfi: ða:lika 1 Gas $^{\varsigma}$ ri

- was theredevelopment economic in that time

- There was economic development in that time.

This type of processes differs from the relational processes in that they involve only the Existent as a participant, which is in example (xxi) 'the train station'. huna:ka (there) in Arabic signals the Existence of 'a train station'. It therefore signals an existential process. It is different from the deictic 'there' in that it does not point to the 'thing'. Rather, it refers to its existence.

\section{Data and method of analysis}

As pointed out earlier, the analysis will investigate whether the experiential structure in the headlines, correlate with the gender of the participants. Arabic Newspaper texts will be analysed to see the way the textual 
function represents men and women in discourse. To achieve this purpose, I will begin first by investigating two comparable stories from the Moroccan popular newspapersto see how the two genders are linguistically represented in them. The first text (Text A) deals with a crime a woman committed against her elderly husband, whereas the second one(Text B) recounts the story of two young men murdering an elderly woman. This will be followed by the quantitative analysis of another six newspaper texts to confirm the findings reached through the analysis of text A and B. The aim is to discover whether similar results can be found by comparing the statistical findings of the analyses, to see whether there is any gender-related pattern emerging in the discourse of these texts.

But prior to analysing the core texts, the study will start first by looking at headlines. A total of 158 headlines (the headlines are in appendix I), randomly selected, will be examined. They will be studied separately as they constitute distinctive unitswith their own structure and function in news reports. They are adjuncts to the body copy and "are usually visually distinct, set in different typefaces or sizes to the body copy" (Bell 1991: 15). In this study,they will be divided into two groups: the first contains headlines talking about men criminals, whereas the second is constituted of headlines related to women criminals. This will permit the comparison of the two sets of headlines for any gender differences. The headlines related to men constitute a majority if compared with the number of headlines related to women: Men are talked about in the overwhelming majority, $83 \%$ of the headlines. By contrast, women are mentioned only in 26 headlines, a percentage of $18 \%$. This huge difference bears significance in itself, showing that men overwhelmingly dominate the Moroccan popular newspapers.

\section{Men's representation in the headlines}

In the men's set of headlines, the participant carrying out the action is presented in a variety of ways through the transitivity system. As will be shown through the analysis, men who performed the criminal action are not all the time assigned the participant role of the Actor of a material process.

\subsection{The quantitative study: Headlines}

It is worth mentioning that the study will take the clause as a unit to carry out the quantitative analysis of the headlines. The types of processes employed in each set of headlines will be quantified to contrast the kind of processes and some participant roles associated with women and with men.

\subsubsection{Types of processes}

As the figures below show, there is a marked difference between man and women, especially in material processes:
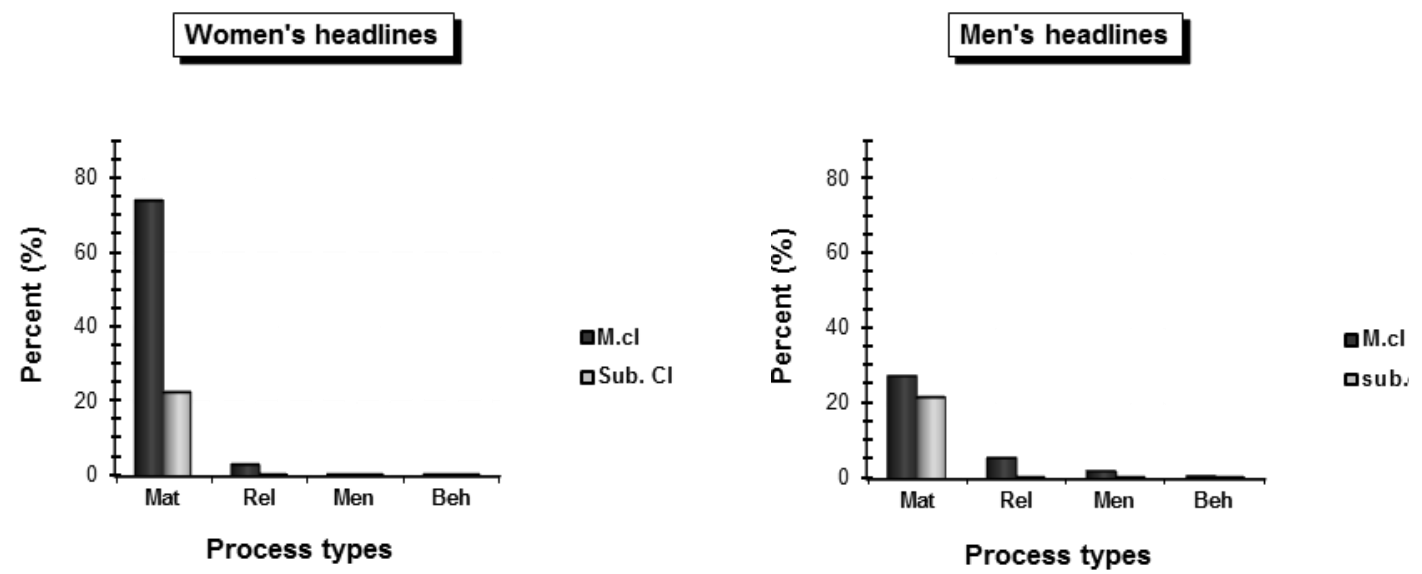

Fig. 1 Percentage of occurrence of the different types of processes used in headlines in main and subordinate clauses according to gender (Mat: Material processes; Rel: Relational processes; Men: Mental processes; Beh: Behavioural processes; M.Cl: Main clauses; Sub.cl: Subordinate clauses).

In the women's group of headlines, material processes are used with the frequency of $74.1 \%$ of the main clauses, whereas in the men's set of headlines, the occurrence of this type of processes is conspicuously lower with a frequency of $27.4 \%$. Subordinate clauses also contain some material processes with a percentage of $22.58 \%$ for women, and $21.83 \%$ for men.

As regards other types of processes found in the headlines, relational processes are used in $5.63 \%$ of men's headlines, whereas they are used once only in a subordinate clause in women's headlines, having the frequency of $3.22 \%$. Mental processes occur in $2.11 \%$ in men's headlines, while they occur in one subordinate 
clause in women's set of headlines (3.2\%). Behavioural processes were found in $0.77 \%$ of men's headlines and none was found in women's set.

\subsubsection{Actor VS Goal}

The participant role of the Actor and the Goal associated with material processes is another characteristic distinguishing men and women in the headlines. Material processes are dominant if compared with other types of processes:
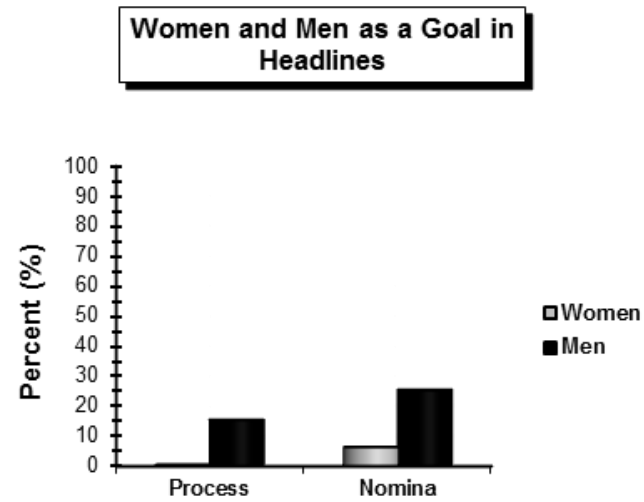

\section{Women and Men as an Actor in} Headlines

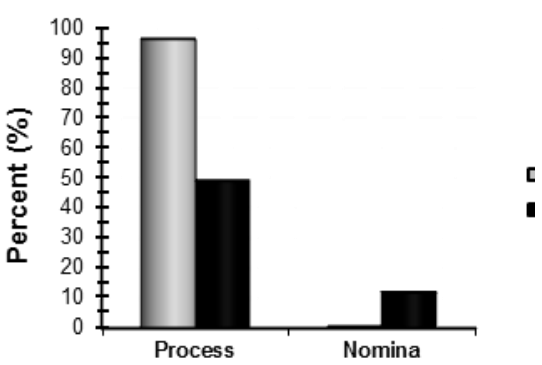

Fig. 2 The percentage of men and women as Goals and Actors of processes and nominalisations in headlines (Process: Processes; Nomina: Nominalisation).

Prior to discussing the statistical findings displayed in the graphs above, it is worth pointing out that the action can be either presented as a process in the clause i.e. a verb requiring a subject in the clause which is generally the Actor when the process is of the material type as in 'John kills the snake' where 'John' is the subject as well as the Actor of the material process 'to kill', or a nominalisation of the process which would involve the use of a noun derived from the verb. This would lead to the omission of the subject from the surface structure of the clause, hence the Actor when the nominalised process is a material one. In a sentence like 'The killing of the snake took a few minutes'; 'the killing' is the nominalisation of the material process 'to kill'. And because a nominalised process is used, the Actor of the action does not appear on the surface structure. Despite the omission of the participant roles of the Actor, and sometimes also the Goal of the action from the clause when the process in nominalised, the reader has most of the time the ability to infer who carries out the nominalised material process and to whom it is direct from the context of use.

Going back to the graphs above, the woman is assigned the transitivity role of the Actor in material processes in $96.68 \%$. Men on the other hand, show the frequency of $49.29 \%$ as Actors of material processes, and of $11.97 \%$ as the implied Actors of nominalizations.Men also occur with a higher frequency relatively to women as Goals of material processes. In $15.49 \%$ of the men's set of headlines, men occur as Goals of material processes and in $25.35 \%$ as Goals of nominalised actions carried out by the authorities. On the other hand, women are assigned the transitivity role of the Goal only of one nominalised action with the frequency of only $6.4 \%$, noticeably lower than men. They do not occur as Goals of material processes.

If one compares the general frequency of men and women as Actors and Goals, regardless of whether they are the Actors or Goals of processes or nominalised processes, a substantial difference can be noticed.Men occur with a percentage of $40.84 \%$ as Goals while women are substantially lower with the frequency of $6.4 \%$. As far as the participant role of the Actor is concerned, women exceed men by having the highest percentage of $96.68 \%$ whereas men are $61.26 \%$.

Figure 1 shows clearly this gender difference in newspaper headlines concerning the participant roles of Actors and Goals: 


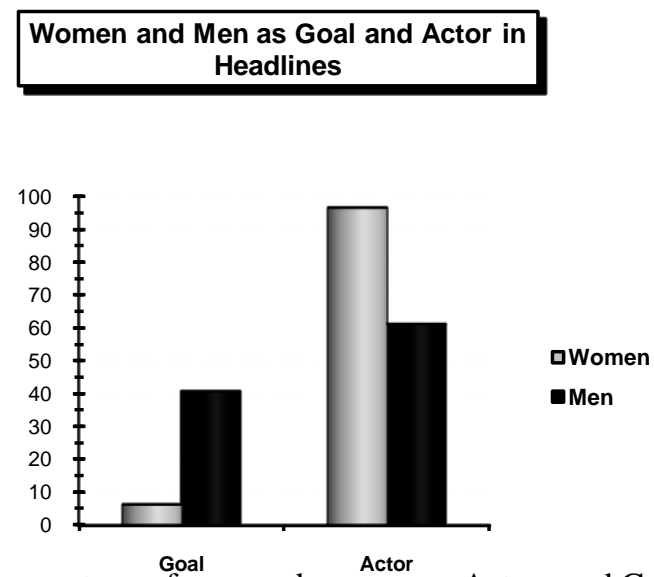

Fig. 3 General percentage of men and women as Actors and Goals in headlines.

\subsection{Core analysis of Text $A$}

The following part will be concerned with the quantitative study of the representation of men and women at the level of the experiential function of newspaper core texts. I will look at the process types with which the woman in text $\mathrm{A}$ and the men in text $\mathrm{B}$ are associated. This will be achieved by counting the frequency of occurrence of the various types of processes in the two texts.

\subsubsection{Quantitative analysis}

The results obtained from the statistical work can be best summarised in the following two graphs:
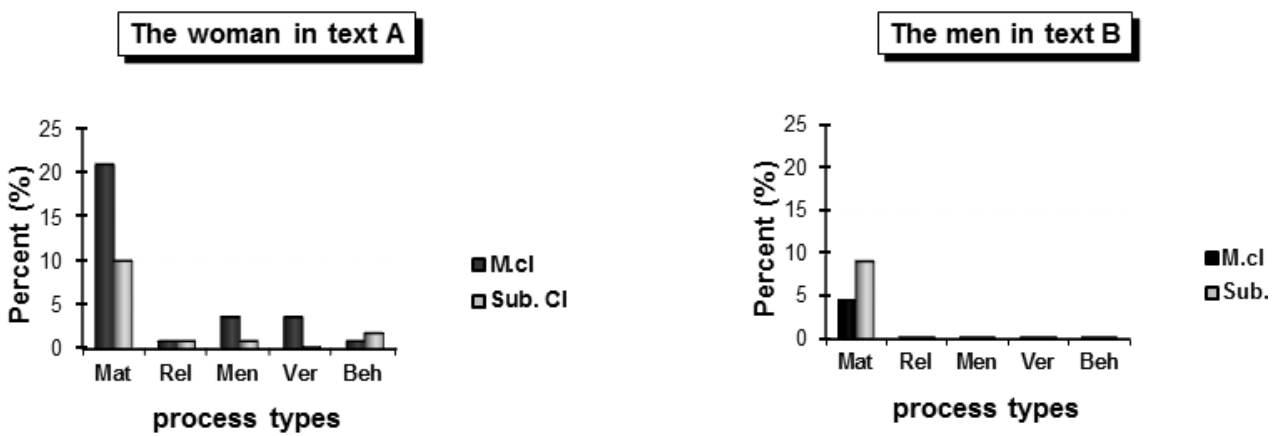

Fig. 4 Percentage of occurrence of the different types of processes in text A and B in main and subordinate clauses according to gender (Mat: Material processes; Rel: Relational processes; Men: Mental processes; Ver: Verbal processes; Beh: Behavioural processes. M.Cl: Main clauses; Sub.Cl: Subordinate clauses).

As can be seen in figure 4.4, the two texts display contrasting patterns in the way processes are used. Processes in text A are varied. By contrast, text B does not display such variety in the processes related to the two men. They carry out material processes with a frequency of $4.5 \%$ in main clauses, while they occur in $9.09 \%$ in clauses with a subordinate status. They are not mentioned as participants in any other type of processes in the text.

On the other hand, the woman in text $\mathrm{A}$ is shown differently by being mentioned as a participant in many types of processes. She is, however, in most of the processes, presented as carrying out material processes. This occurs in $20.9 \%$ in main clauses and in $10 \%$ in subordinate clauses. This means that the woman is presented in the majority of instances as an active performer of material actions which have an effect on the external world. Most of her actions affect the victim.

As figure 4.4 above shows, the woman is also found as a participant in mental processes in $3.63 \%$ of the main clauses and in $0.90 \%$ in subordinate clauses. She occurs in $3.63 \%$ as a Sayer in verbal processes. She is also shown as performing behavioural processes in $0.90 \%$ of main clauses and in $1.81 \%$ of subordinate clauses. Relational processes have the low occurrence of only $0.90 \%$ in main clauses and also in subordinate ones. As can be clearly seen, the woman in text A is presented more often than the two men in text B as an active participant. If the overall percentage is counted to know the frequency of occurrence of the woman as a 
participant, we will have $43.57 \%$ of the clauses containing the woman as actively performing a process involving volition. This is suggestive especially when compared with the percentage of the occurrence of the men as active participants in text $\mathrm{B}$, which is only $13.59 \%$.

The frequent occurrence of the woman as an active participant stresses the fact that she is guilty of killing her husband, even if the action of killing might have been unpremeditated, (e.g. In text 1, the woman was having a fight with her husband, she might have accidentally killed him). By contrast, the two men who willingly raped the woman and premeditatedly murdered her are not shown with the same frequency as active participants in the crime.

In order to reinforce that the Moroccan popular newspapers tends to represent men and women in different ways, the study will analyse six more newspaper texts to see in a clearer way the tendency of the results. These texts were also examined for the way women and men criminals were depicted in the transitivity structure. The results obtained also suggest that men and women criminals are portrayed differently. As the statistical results reveal (see table 1 below), more emphasis is laid upon women's actions as they occur in higher percentages as Actors in material processes in the newspaper texts. Thus, their agency stands out more than men's:

\begin{tabular}{|c|c|c|c|c|c|c|c|c|c|c|}
\hline & \multicolumn{2}{|c|}{$\begin{array}{l}\text { Material } \\
\text { processes }\end{array}$} & \multicolumn{2}{|c|}{$\begin{array}{c}\text { Relational } \\
\text { processes }\end{array}$} & \multicolumn{2}{|c|}{$\begin{array}{c}\text { Mental } \\
\text { processes }\end{array}$} & \multicolumn{2}{|c|}{$\begin{array}{c}\text { Verbal } \\
\text { processes }\end{array}$} & \multicolumn{2}{|c|}{$\begin{array}{c}\text { Behavioural } \\
\text { processes }\end{array}$} \\
\hline & $\begin{array}{l}\mathrm{M} . \\
\mathrm{Cl}\end{array}$ & $\begin{array}{l}\mathrm{Sub} . \\
\mathrm{Cl}\end{array}$ & $\begin{array}{l}\mathrm{M} \\
\mathrm{Cl}\end{array}$ & $\begin{array}{l}\mathrm{Sub} . \\
\mathrm{Cl}\end{array}$ & $\begin{array}{l}\mathrm{M} . \\
\mathrm{Cl}\end{array}$ & $\begin{array}{l}\mathrm{Sub} . \\
\mathrm{Cl}\end{array}$ & M. $\mathrm{Cl}$ & $\begin{array}{l}\text { Sub.C } \\
l\end{array}$ & $\begin{array}{l}\mathrm{M} \\
\mathrm{Cl}\end{array}$ & $\begin{array}{l}\mathrm{Sub} . \\
\mathrm{Cl}\end{array}$ \\
\hline Text A1 & 21.2 & 9.1 & 3 & - & - & - & 3 & - & - & - \\
\hline Text B1 & 4.5 & 4.5 & 6 & 1.5 & - & 1.5 & - & - & 1.5 & - \\
\hline Text A2 & 27.2 & 5.4 & 4.4 & 1.1 & 1.1 & - & 5.4 & 11 & - & - \\
\hline Text B2 & 3.7 & 2.5 & - & - & - & - & - & - & - & - \\
\hline Text A3 & 28.6 & 7.1 & - & 0.7 & 12.2 & 1.5 & 2.9 & 0.7 & 2.1 & - \\
\hline Text B3 & 7.6 & 0.9 & 2.9 & - & 1.9 & 0.9 & 2.9 & - & 0.9 & - \\
\hline
\end{tabular}

Table. 1 Percentage of occurrence of women and men as performers of different types of process. Texts A1, A2 and A3 are women's texts (light grey). Texts B1, B2 and B3 are men's texts (dark grey).(M.Cl: Main clause; Sub.Cl: Subordinate clause).

The explanation advanced to interpret the differences found between men and women in the language of Moroccan popular newspapers is that women criminals do not conform to the stereotypical image associated with them. Women committing crimes, especially crimes associated with physical strength and violence do not fit into the images which constitute the norm that people hold about women in the Moroccan society. On the other hand, violence and physical strength does not contrast with masculinity and is even considered one of its main characteristics. It is viewed as normal for men to be physically strong and violent, hence aggressive crimes that they commit are not considered as marked or unusual.

These different images held within the Moroccan society can be said to be the result of the two genders expressing their different identities as two different subcultures through the use of language. This interpretation belongs to what is called the difference approach. Women are not identified through physical strength and violence, and generally rely more on notions such as tenderness and motherhood to signal their different identity form men. By contrast, men distinguish themselves by associating themselves with physical strength and aggressiveness in the Moroccan society, therefore signalling their different group.

However, one might argue that this difference does not purely spring from the desire to mark different subcultures, but is in itself a symptom to an underlying power relationship existing between the two genders, hence taking the deficit approach. Women, by not being supposed to be endowed with physical strength, are not expected to act violently. They are on the other hand expected to seek help and protection from men, who are considered as acting normally when they carry out aggressive actions. It does not run counter to their supposed nature. The underlying assumption from this is that women, as a group, are not only shown in this manner to mark their different identity and subculture but to also present them as the powerless and weak gender which needs the control of men, the powerful group, in order to handle some situations.

The linguistic examination of the newspaper texts brings to light that these ideologies related to gender are reproduced and consolidated in the linguistic structure of the Moroccan popular newspaper. They are presented as the established common sense to the reader. They are, by this, consolidated and perpetuated as the norm around which gender identities should be built in Moroccan popular culture. 


\section{Conclusion}

In my study of the representation of gender in the Moroccan tabloids, I have set out to examine the language of the Moroccan popular newspapers using a CL approach. My main objective was to discover whether it displays a difference correlating with the gender of the participants in the articles. The study did not restrict itself to merely analysing texts qualitatively and focused instead on quantifying the linguistic features of interest, to find out whether they display a suggestive pattern correlating with the gender of the participants in the newspapers. The results showed that the texts under study represent men and women unequally at the level of the experiential function, exhibitinggender-related differences, which can be best seen when one looks at material processes. As the statistics show, women occur as Actors in material processes far more frequently than men, which is an indication that women's agency is emphasised more than men's. This happens in spite of the fact that the crimes men commit are sometimes farmore serious that the ones committed by women.

The analysis of the news reports shows that a criminal woman in Morocco is considered deviant because she goes against some stereotyped images and does not fit in with some fundamental structures; and one of the images associated with women is that of the mother (Hutter and Williams 1981:17).This stereotyped image incarnates the notion of care, tenderness and maturity. These notions are lost when a woman commits a crime, which is considered more as a male activity. It is inconceivable for a woman to commit violent crimes as it contradicts the nurturing notion of motherhood. The woman criminal flouts one of the strongly established and implicit norms within society. "It is not easy to flout explicit norms of behaviour but it is very much harder to question norms which are not articulated at all" (Hutter and Williams 1981: 10). She is blamed because her behaviour contradicts "the stereotype of the "normal' female personality in that they do not embody the specific feminine qualities of docility, gentleness and frailty." (Rowett and Vaugham1981: 131).

Violence is however associated more with men and masculinity. The general stereotyped image about men is that they have the tendency to lose their temper more easily than women and that they are endowed with more physical strength which justifies the violence they commit. They like risk taking and are aggressive and violent (Dobash, Dobash and Noaks 1995:2). Male deviancy is not as stigmatised as the female one. Their deviancy is generally approved of and is positively depicted (Heidensohn 1996: 98). In some studies, male delinquents are found to be portrayed as heroes, while female delinquency is considered role-inappropriate (Heidensohn 1996:125, 129). It is generally considered normal for men to be involved in violent physical activities. This explains why women offenders in the discourse of the Moroccan popular press are shown as the deviationfrom the norm, by emphasizing their agency, henceshowingless tolerance towards it in comparison to men's agency.

\section{References}

[1] R. Fowler, R. Hodge, and G. Kress, Language and Control (London: Routledge and Kegan Paul, 1979).

[2] R. Fowler, Language in the News: Discourse and Ideology in the Press (London: Routledge, 1991).

[3] H.G. Widdowson, The theory and practice of critical discourse analysis.A review article', Applied Linguistics, 19 (1), 1998, 136-51.

[4] N. Fairclough and R. Wodak, Critical Discourse Analysis, in T.A. Van Dijk (Ed.), Discourse as Social Interaction (London: Sage, 1997) 259-284.

[5] M.A.K. Halliday, An Introduction to Functional Grammar (London: Edward Arnold, 1994).

[6] M.A.K. Halliday, System and Function in Language; Selected Papers edited by G.R. Kress (London: Oxford University Press, 1976).

[7] M.A.K. Halliday, Language as Social Semiotic: The Social Interpretation of Language and Meaning (London: Edward Arnold, 1978).

[8] J.R. Martin, C. Matthiessen and C. Painter, Working with Functional Grammar (London: Arnold, 1997).

[9] G. Thompson, Introducing Functional Grammar (Arnold: London, New York, Sydney, Auckland, 1996).

[10] A. Bell, The Language of News Media (Oxford: Basil Blackwell, 1991).

[11] B. Hutter and G. Williams, (eds) Controlling Women: the Normal and the Deviant (Croom Helm London \& Oxford University Women's studies committee: 1981).

[12] C. Rowett and P.J. Vaughan, Women and Broadmoor: Treatment and Control in a special hospital, in B. Hutter and G. Williams (eds), Controlling Women: the Normal and the Deviant (London: Croom Helm and Oxford University Women's studies committee, 1981) 131-153.

[13] R. E. Dobash, , R. P Dobash and L. Noaks, Thinking about gender and crime, in R.E. Dobash, R.P. Dobash and L. Noaks (eds), Gender and Crime (Cardiff: University of Wales press, 1995) 1-15.

[14] F. Heidensohn, Women and Crime (Basingstoke: Macmillan, 1996). 